\title{
Atlantoaxial Stabilization by Posterior C1 and C2 Screw-Rod Fixation for Various Pathologies: Case Series and Comprehensive Review of Literature
}

\author{
Chandramohan Unni ${ }^{1} \quad$ Vijayan Pettakkandy ${ }^{1} \quad$ Abdul Jaleel P. ${ }^{1} \quad$ Subrat Kumar Soren ${ }^{1} \quad$ Vineeth K.K. ${ }^{1}$ \\ ${ }^{1}$ Department of Neurosurgery, Government Medical College, \\ Kozhikode, Kerala, India \\ Address for correspondence Subrat Kumar Soren, MCh, B-34, BHEL \\ EPD Township-A, 19th Cross, Malleswaram, Bengaluru 560055, \\ Karnataka, India (e-mail: drsubratsurgery@gmail.com).
}

J Neurosci Rural Pract 2021;12:228-235.

\begin{abstract}
Keywords

- atlantoaxial dislocation

- C1-C2 fixation

- os odontoideum

- odontoid fracture

- rheumatoid arthritis

- neuroanatomy

- C1 lateral mass

- C2 pedicle

We retrospectively analyzed atlantoaxial dislocation (AAD) of various pathologies, namely, rheumatoid arthritis (RA), os odontoideum, and trauma. Various techniques were discussed in relation to $\mathrm{C} 1-\mathrm{C} 2$ stabilization. The study aims to share our clinical experience in a series of six cases of $\mathrm{C} 1-\mathrm{C} 2$ instability that underwent posterior C1-C2 fusion, with free hand technique and limited fluoroscopy. The clinicoradiological presentation for each patient is described. We reviewed different literatures related to our case vividly and focused on the basic neuroanatomy involved in the atlantoaxial joint. All patients of AAD had evidence of severe canal compromise and chronic compressive spinal cord changes. In our study, the patients age ranged from 28 to 52 years. The study included four males and two females. Out of six patients of AAD, three had history of trauma, two had os odontoideum, and one had chronic inflammatory condition (RA). From our case series, we concluded that the Goel-Harms technique is the most versatile and surgeon friendly technique for $\mathrm{C} 1-\mathrm{C} 2$ fixation. Early recognition and surgical intervention of atlantoaxial joint instability is essential to prevent catastrophic neurological complications.
\end{abstract}

\section{Introduction}

Traditionally, there are several surgical management techniques used to manage $\mathrm{C} 1-\mathrm{C} 2$ instability such as the Gallie, Brooks-Jenkins, or interspinous methods..$^{1-3}$ Unfortunately, studies have shown that the nonunion rates for these techniques are as high as $80 \%$ (range, $3-80 \%$ ) even with the use of postoperative immobilization such as the halo vest. ${ }^{4}$ These unsatisfactory outcomes led to the development of newer techniques for $\mathrm{C} 1-\mathrm{C} 2$ fusion instrumentation, including the use of C1-C2 transarticular screws. ${ }^{5}$ Although biomechanically superior to the wiring techniques, the Magerl technique is contraindicated in obese patient and in patients with increased thoracic kyphosis. ${ }^{6}$ Further, this technique also requires preinstrumentation reduction of any subluxation. In 1994, Goel and Laheri reported the use of plates and C1 lateral mass and C2 pars interarticularis screws. ${ }^{7}$ In 2001, Harms and Melcher further popularized the technique of posterior $\mathrm{C} 1-\mathrm{C} 2$ fusion with $\mathrm{C} 1$ lateral mass screw and C2 pedicle screw. ${ }^{8}$ Although this technique is technically challenging, but it has showed superior biomechanical and clinical results. The advantages of the new technique (Goel-Harms) are safer trajectory of the screws, potential for postinstrumentation reduction, and avoidance of damage to the $\mathrm{C} 1-\mathrm{C} 2$ facet joint, and this makes it superior to other $\mathrm{C} 1-\mathrm{C} 2$ fusion in terms of reduction of $\mathrm{C} 1-\mathrm{C} 2$ subluxation, which leads to improved indirect decompression of the spinal cord. Harms published online March 3, 2021
DOI https://doi.org/

10.1055/s-0041-1722838 ISSN 0976-3147. (c) 2021. Association for Helping Neurosurgical Sick People.

This is an open access article published by Thieme under the terms of the Creative Commons Attribution-NonDerivative-NonCommercial-License, permitting copying and reproduction so long as the original work is given appropriate credit. Contents may not be used for commercial purposes, or adapted, remixed, transformed or built upon. (https://creativecommons.org/licenses/by-nc-nd/4.0/).

Thieme Medical and Scientific Publishers Pvt. Ltd. A-12, 2nd Floor, Sector 2, Noida-201301 UP, India 
and Melcher reported a 100\% fusion rate. Preoperative bony anatomy of cervicomedullary junction and vertebral artery are mandatory in planning the procedure to avoid catastrophic complications.

This study aims to share our clinical experience in a series of six consecutive cases of various pathologies of atlantoaxial dislocation (AAD), which underwent posterior C1-C2 fusion, using the $\mathrm{C} 1$ lateral mass screw and $\mathrm{C} 2$ pedicle/pars screw with free hand and under limited fluoroscopy. We used titanium polyaxial screw and rod systems, and the length of the screw was determined preoperatively from CT scan. This technique was found to be surgeon friendly, statistically reliable, and led to reproducible results if bony anatomy of craniovertebral junction (CVJ) was conducive to the surgery. We described the clinicoradiological presentations of each patient and also reviewed the literatures related to our case comprehensively.

\section{Illustration of Cases}

\section{C1-C2 Instability in Rheumatoid Arthritis (RA)}

\section{Patient 1 (-Fig. 1)}

A 46-year-old female presented with progressive neck pain and minimal difficulty in walking for the past 5 years. The pain was radiating to bilateral posterior shoulders and more onto her left arm. The neck pain worsened with movement, but she had no complaints of numbness, tingling and gross weakness in extremities. On examination, it was found that she had normal higher mental function, tone was increased in both upper limbs, power of the limb was normal, tandem walk was not possible, and Hoffman's sign positive, more marked on left side. There was an exaggerated reflex in bilateral upper and lower limbs, but jaw jerk was absent. Patient was on medication for RA prior to surgery (-Fig. 1A, B); X-ray of C-spine showed mild increase in atlantodental interval (ADI) and osseous erosion at C1 and C2 level ( $\sim$ Fig. 1D); atlantodental distance was apparently increased with abnormal hypointense soft tissue and abnormal spinolaminar line at CVJ ( - Fig. 1C, E). CT scan shows erosion, sclerosis, partial fusion of left atlantoaxial facet, mild increased ADI $4.4 \mathrm{~mm}$, and cortical irregularities, with bone formation noted in the anterior arch atlas. There were end plate irregularities and sclerosis at multiple vertebral levels too. No evidence of basilar invagination (-Fig. 1F): postoperative C-spine.

\section{Os Odontoideum}

Patient 2 (-Fig. 2)

A 35-year-old female patient, with history of fall in the bathroom 9 months back, presented to us with progressive neck pain radiating to bilateral shoulder and also complained of numbness and progressive weakness in her both upper limb (Medical Research Council [MRC] grade 4/5) and lower limbs (MRC grade 5/5) for the last 3 to 4 weeks. Patient had no bladder and bowel involvement.

CT and MRI scan of spine done revealed os odontoideum dystopic type with atlantoaxial dislocation along with T2 hyperintensity at C2 suggestive of myelomalacia. X-ray C-spine shows os odontoideum ( - Fig. 2A). CT C-spine shows os odontoideum ( - Fig. 2B). MRI C-spine shows atlantoaxial dislocation with spinal cord compression and T2 hyperintensity suggests myelomalacia ( - Fig. 2 C).
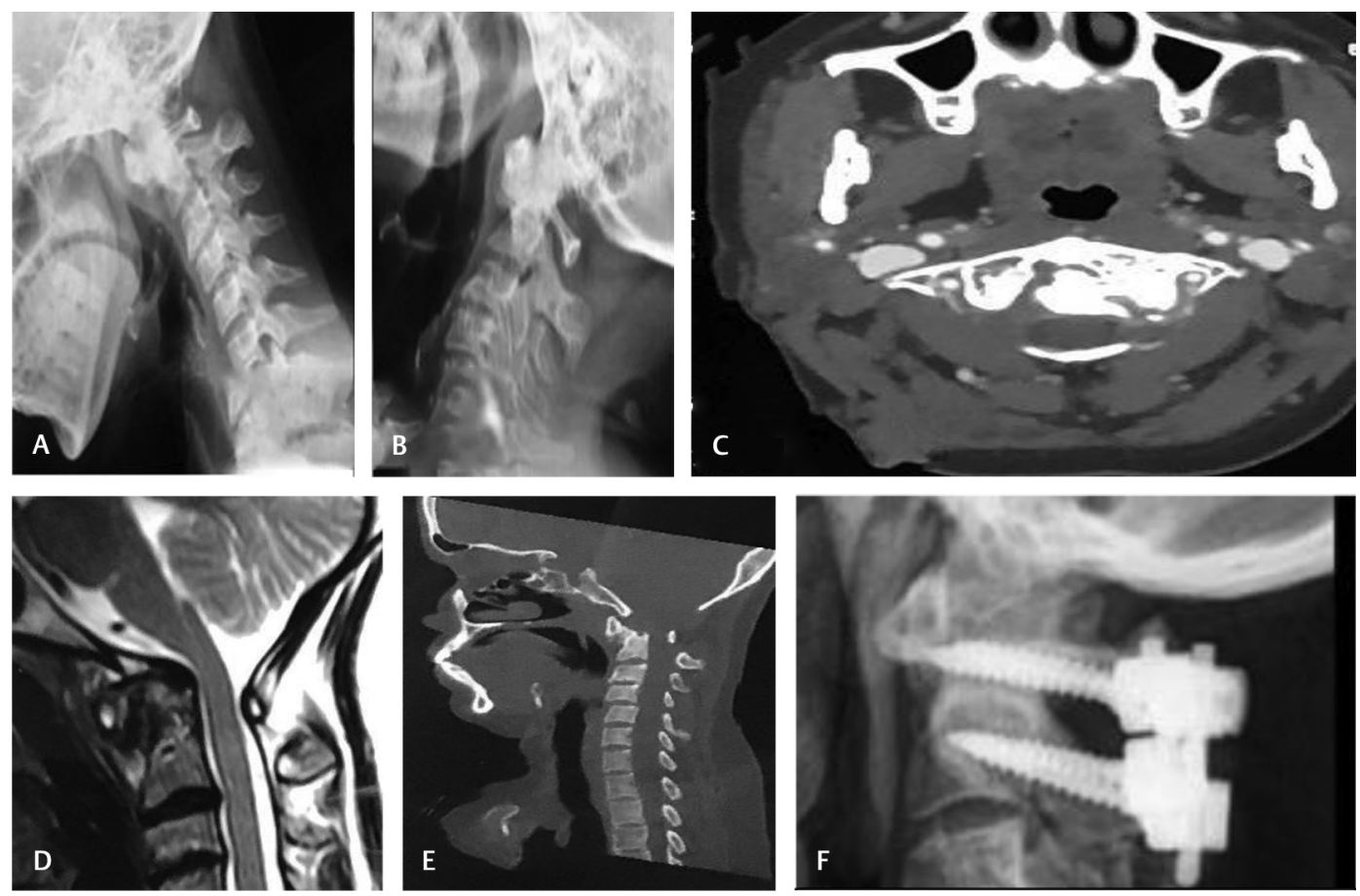

Fig. 1 (A-F) Images of patient 1. 

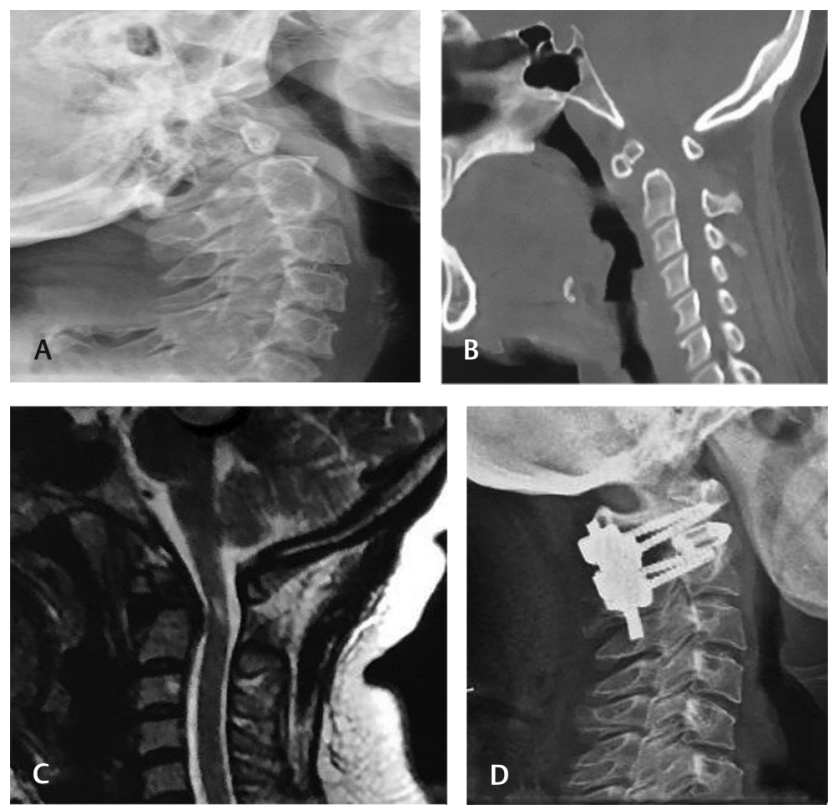

Fig. 2 (A-D) Images of patient 2.

X-ray C-spine anteroposterior view with C1-C2 fusion and stabilization ( - Fig. 2D).

Patient 3 (-Fig. 3)

A 52-year-old male manual laborer presented with neck pain following sudden lifting of weight on his head. But for the last 2 months, pain severity had increased significantly with restriction of neck movements. Also, patient had numbness and weakness in bilateral upper limbs, which had progressed to both the lower limbs over the course of 2 months. On examination, there was hypertonia, exaggerated reflexes, Hoffman's positive both sides, and Nurick grade 3. C-spine X-ray (lateral-flexion and extension view) was suggestive of atlantoaxial dislocations ( - Fig. 3A, B). CT scan revealed os odontoideum with hypertrophied and sclerotic anterior arch of atlas. C1/C2 subluxation was noted with sclerosis and cystic changes in right half of $\mathrm{C} 1$ and vertebral body (-Fig. 3C, D). MRI revealed smooth well corticated ossicle of size $9.4 \times$ $8 \mathrm{~mm}$ superior to dens. Anterior subluxation of atlas over axis was noted with atlantodental distance, narrowing of spinal canal at the same level with thinning of spinal cord and T2 hyperintensity at CVJ and upper cervical canal level (-Fig. 3E,F). - Fig. 3G shows postoperative image.

\section{Odontoid Fracture and Atlantoaxial Dislocation (AAD) Patient 4}

A 46-year-old male presented to us with history of fall following slippage and sustained neck trauma for 3 months. Patient had neck pain and numbness on both upper limbs and was progressive for the last 1 month. On examination, there was hypertonia, Hoffman's sign positive and bilateral plantar extensor. The gait was spastic, and there was no bladder and bowel involvement. The patient was subjected to investigation and $C$ spine X-ray showed atlantoaxial instability be (AAI). CT CVJ showed odontoid fracture involving the base of the odontoid with anterior displacement of proximal fracture fragment and spinal canal narrowing (odontoid fracture-type III). MRI revealed fracture odontoid without evidence of myelomalacia ( - Fig. 4A). MRI sagittal showed fracture at the base of odontoid process and posterior subluxation causing spinal canal stenosis and cord compression ( - Fig. 4B). CT sagittal section of spine revealed odontoid fracture at the base of odontoid process with anterior displacement of proximal fracture fragment and spinal canal narrowing ( - Fig 4C); Goel-Harms technique.

\section{Patient 5}

A 37-year-old male patient came to our hospital with a history of fall 8 years back with neck pain, features of myelopathy, and Nurick grade 3. CT sagittal spine shows anterior displacement, angulation of odontoid fracture segment and distal segment displaced posteriorly causing compression at CVJ (-Fig. 5A).
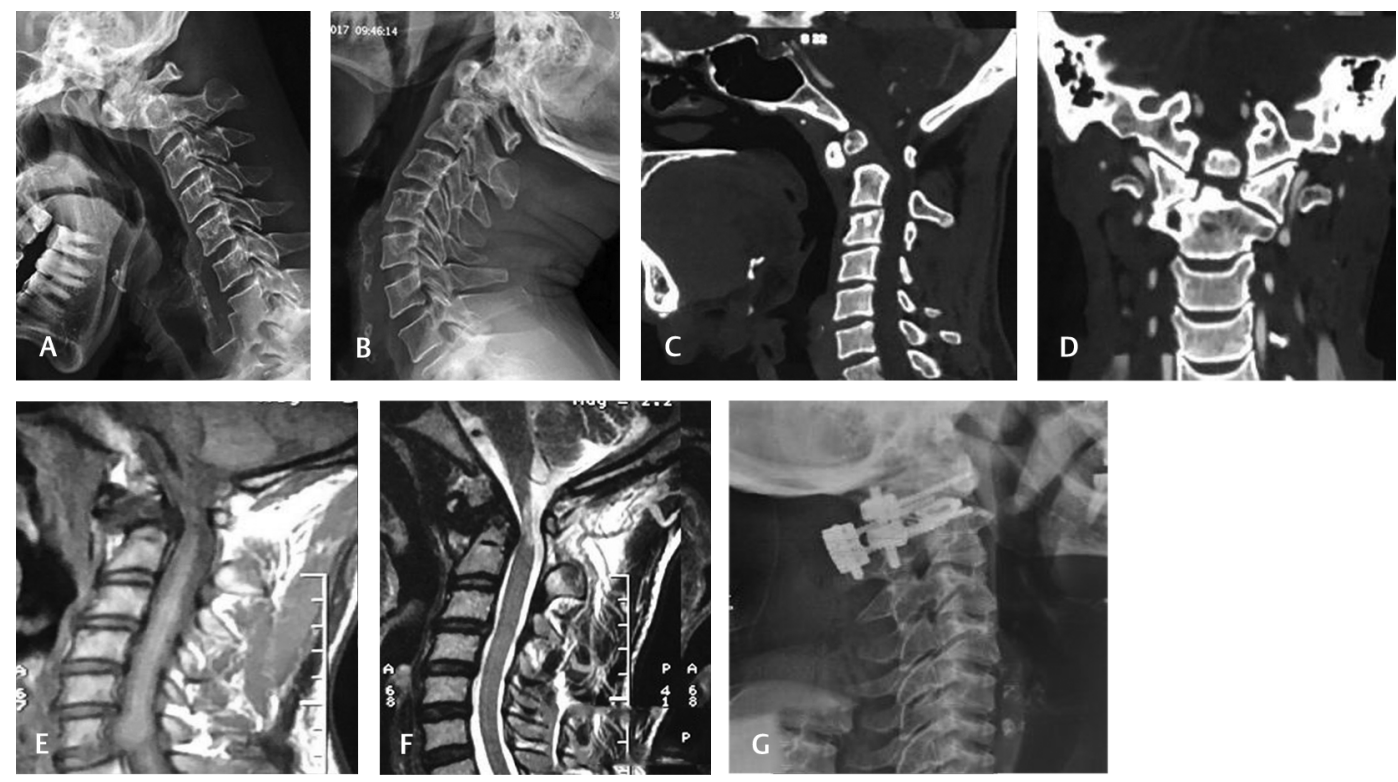

Fig. 3 (A-G) Images of patient 3. 

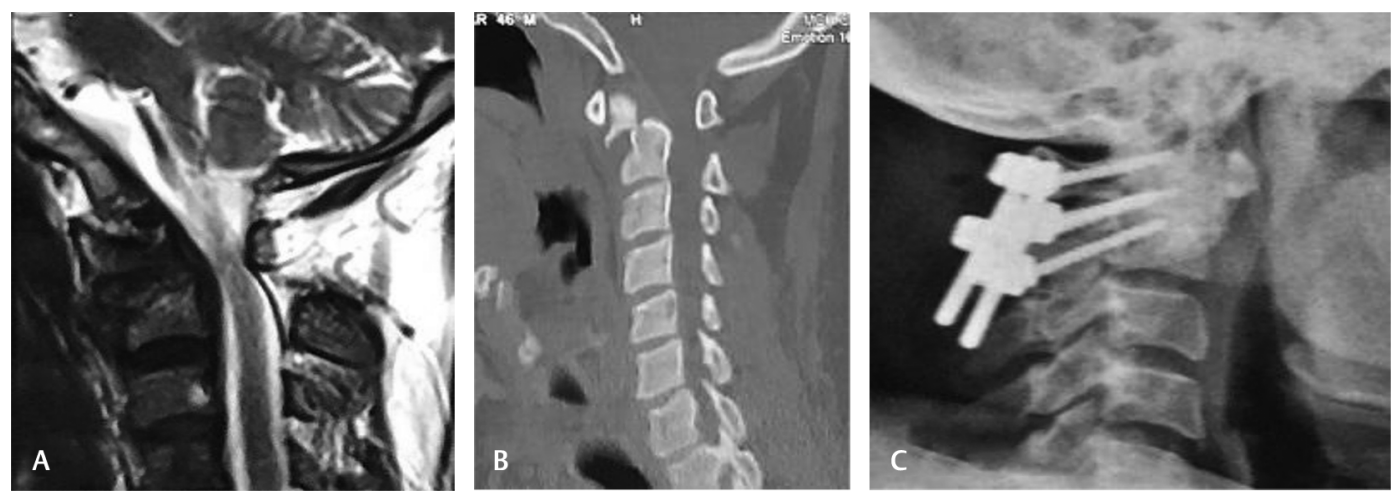

Fig. 4 (A-C) Images of patient 4.
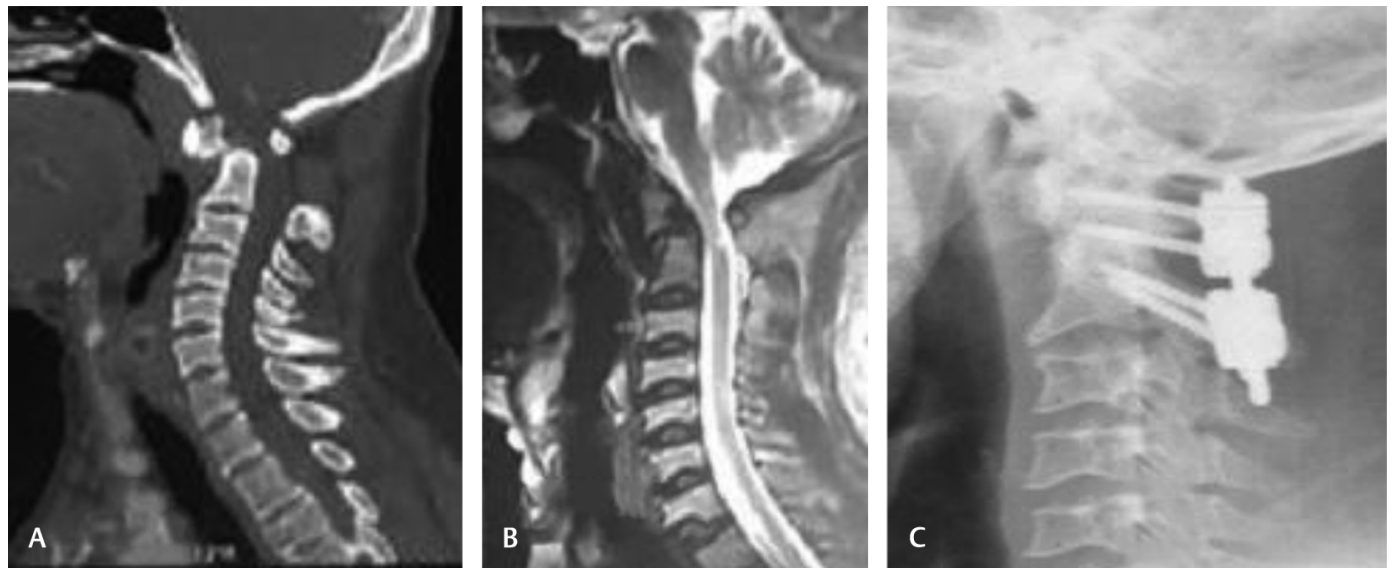

Fig. 5 (A-C) Images of patient 5.

-Fig. 5B shows displaced fracture of odontoid through the base, and fracture segment displaced $5 \mathrm{~mm}$ in sagittal image with narrowing CVJ. X-ray C-spine shows screw and rod in situ (-Fig. 5C).

\section{Patient 6}

A case of a 28-year-old male, with a history of motor vehicle accident 1 year back, presented to us with features of myelopathy and progressive neck pain. MRI T2 sagittal shows exaggeration of cervical lordosis; blunting of $\mathrm{C} 2$ vertebra was noted with evidence of dorsiflexion of $\mathrm{C} 2$ vertebral body, causing compression of spinal cord ( - Fig $6 \mathbf{6 A})$. Altered signal intensity and thinning of spinal cord were noted at CVJ. - Fig. 6B shows fracture involving odontoid process with proximal fracture segment displaced anteriorly, lying in close contact with posterior margin of arch of atlas and distal C2 displaced posteriorly, causing severe spinal cord compromised. C-arm view of C1-C2 screw and rod fixed in situ (-Fig. 6C). 3D CT reconstruction image depicting course of vertebral artery and anatomy of $\mathrm{C} 1-\mathrm{C} 2$ is shown in -Fig. 6D.

\section{Surgical Outcome}

The age of the patients ranges from 28 to 52 years ( - Table $\mathbf{1}$ ). Four male and two female patients were selected in the study. Out of six patients of AAD, three had history of trauma,
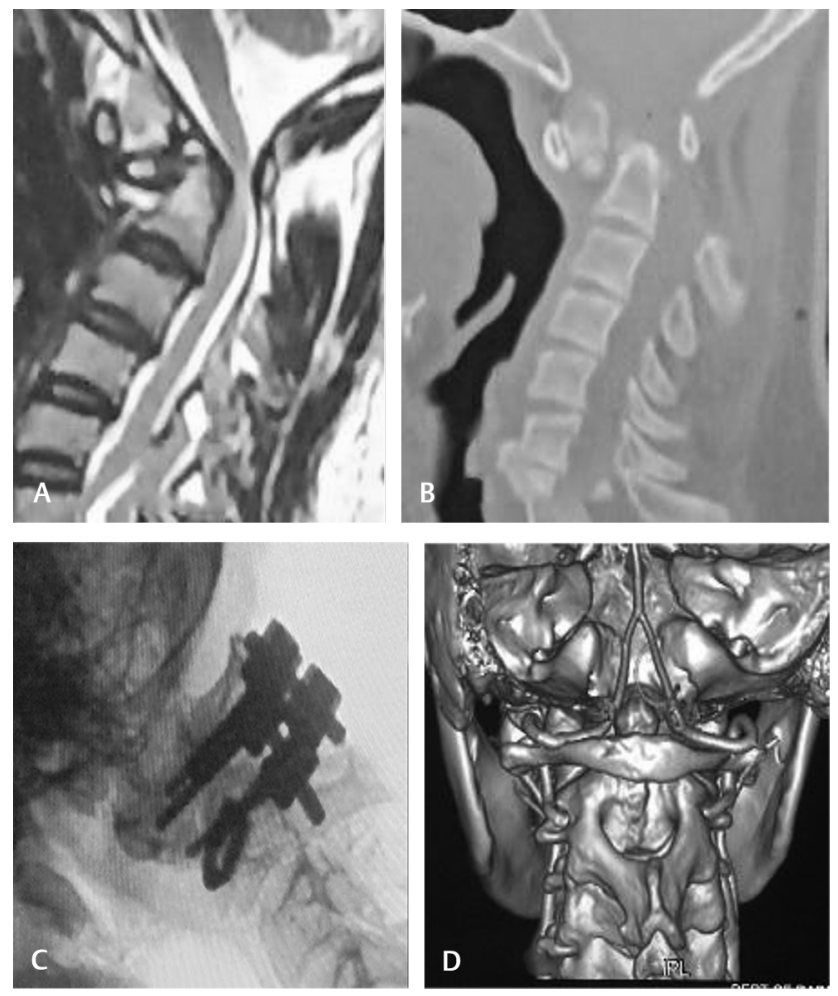

Fig. 6 (A-D) Images of patient 6. 
Table 1 Patient profile

\begin{tabular}{|l|l|l|l|l|l|l|l|}
\hline $\begin{array}{l}\text { Patient } \\
\text { number }\end{array}$ & $\begin{array}{l}\text { Age (in } \\
\text { years) }\end{array}$ & Sex & Diagnosis & Procedure & Myelomalacia & $\begin{array}{l}\text { Preoperative } \\
\text { symptoms }\end{array}$ & Remarks \\
\hline 1 & 46 & F & AAD, RA & $\begin{array}{l}\text { C1 lateral } \\
\text { mass screw }+ \\
\text { C2 pedicle + } \\
\text { spacer }\end{array}$ & Neck pain, numb- & Improved \\
\hline 2 & 35 & F & $\begin{array}{l}\text { Os odontoideum + } \\
\text { AAD }\end{array}$ & C1-C2 Fusion & Yes & Neck pain, NG-III & Improved \\
\hline 3 & 52 & M & $\begin{array}{l}\text { Os odontoideum + } \\
\text { AAD }\end{array}$ & C1-C2 Fusion & Yes & Neck pain, NG-III & Improved \\
\hline 4 & 46 & M & \#Odontoid, type-III & C1-C2 fusion & & Neck pain, NG-III & Improved \\
\hline 5 & 37 & M & \#Odontoid & C1-C2 Fusion & Yes & Neck pain, NG-III & Improved \\
\hline 6 & 28 & M & \#Odontoid + AAD & C1-C2 Fixation & Yes & Neck pain, NG-IV & Improved \\
\hline
\end{tabular}

Abbreviations: AAD, atlantoaxial dislocation; F, Female; M, male; NG, Nurick grade, RA, rheumatoid arthritis.

Note: the symbol "\#" denotes fracture.

two had os odontoideum, and one had chronic inflammatory condition (RA). No major intraoperative complications were noted. Five patients were fused with $\mathrm{C} 1$ lateral mass and C2 pedicle, and in one patient, we used pars screw instead of pedicle. The screw placement was satisfactory. No implant failure noted. There was an adequate increase in diameter of spinal canal and alignment. In all the patients, significant improvement was noticed in terms of symptoms, particularly neck pain and numbness. There was considerable increase in Nurick grade in 5 patients which was reviewed after 6 months in outpatient department (OPD) assessment. However in one patient, the improvement was not up to the mark, as there was delay in surgical intervention.

\section{Discussion}

Anderson and D`Alonzo classification of odontoid fractures was based on the anatomic location of the fracture. There are three types of C2 odontoid fractures. Type I: An oblique fracture through the upper part of the odontoid process. Type II: Fracture at the base of the odontoid, as it attaches to the body of C2. Type III: When the fracture line extends through the body of the axis. ${ }^{9}$ Type I fracture is seen in less than $5 \%$ of cases, and Type II fracture is seen in more than $60 \%$ of the cases. Hadley and colleagues modified this classification and described type IIA odontoid fractures, where there were additional chip fracture fragments at the anterior or posterior portion of the fractured base of the dens. It is invariably unstable and leads to nonunion without surgical intervention. ${ }^{10}$ Type III fracture is seen in approximately $30 \%$ of the cases. It extends into the vertebral body and is relatively stable unless severely displaced. ${ }^{11,12}$ The classification systems are helpful to decide the type of treatment to be chosen. The rate of union of the fractures is negatively affected by age of the patient, the extent of fracture displacement, comminution of the fracture, and delay in diagnosis. ${ }^{22}$ The decision becomes difficult to decide the type of treatment, when a type II fracture extends inferiorly to consider a type III fracture. Such intermediate fractures have been referred to as "shallow" or "high" type III fractures. Therefore, these fractures are considered to be in a gray zone between type II and type III fractures for which some surgeons advice fixation as the choice of treatment. ${ }^{1}$ Thus, this difference in opinion leads to confusion. Grauer et $\mathrm{al}^{11}$ proposed a classification system for type II fractures-type II-A, II-B, and II-C, which is also treatment-oriented. Type IIA is defined as a minimally or undisplaced type II fracture with no comminution. These fractures are generally treated with external immobilization. Type IIB is a displaced fracture, extending from anterior-superior to posterior-inferior, or a transverse fracture. These fractures are to be treated with anterior screw fixation following fracture reduction, assuming adequate bone density. Type IIC is a fracture line extending from anteriorinferior to posterior-superior or a fracture with significant comminution. These fractures are generally treated with posterior atlantoaxial stabilization. ${ }^{9}$

The unique characteristics of CVJ are anatomical and biomechanical properties, which distinguish it from the subaxial spine. It contains vital neural and vascular structures. The neurologic deficits occur as a result of injury to brain stem, lower cranial nerves, and vertebral artery.

The atlas lacks a vertebral body and instead articulates with the odontoid process or dens, a bony protuberance extending superiorly from the vertebral body of the axis. The atlas also communicates inferiorly with the axis by flat, wide articular facets. ${ }^{13,14}$

The odontoid process and horizontal facets permit rotation of the skull, the predominate motion of the $\mathrm{C} 1-\mathrm{C} 2$ vertebral junction..$^{15}$ The transverse ligament of the atlas constrains the dens within $3 \mathrm{~mm}$ of the anterior ring of the atlas by bounding the dens posteriorly. ${ }^{16}$

The atlantoaxial instability due to traumatic rupture of transverse atlantal ligament (TAL) can lead to increase in the $\mathrm{ADI}$. The ADI is the space between posterior portion of anterior arch of $\mathrm{C} 1$ and to the anterior portion of the odontoid process. In adults, an ADI less than $3 \mathrm{~mm}$ is considered to be normal. An ADI greater than $5 \mathrm{~mm}$ suggests disruption of both the TAL and accessory ligaments. ${ }^{17}$

Inferior and superior crura arise from the transverse ligament, as it crosses the dens, attaching to the body of $\mathrm{C} 2$ and 
the anterior foramen magnum, respectively. Taken altogether, the transverse ligament and its crura form the cruciform or cruciate ligament. The transverse ligament contributes substantially to the stability of the CVJ, preventing the dens from folding into the midbrain during flexion. The alar ligaments arise from the anterolateral aspect of the dens and attach to the medial aspect of the occipital condyles, inferior to the foramen magnum. The primary function of the alar ligaments is to restrict rotation of the cranium. The alar ligaments are also critical to maintaining stability at the $\mathrm{CVJ}^{18,19}$. Arising from the subclavian artery, the bilateral vertebral arteries progress cephalad via the transverse foramina of the cervical spine. After exiting the transverse foramina of $\mathrm{C} 1$, the vertebral arteries course along the superior surface of the posterior ring of the atlas before turning ventrally to pass through the atlanto-occipital membrane, medial to the superior articular facet. ${ }^{15}$

The atlantoaxial junction is a delicate anatomic complex that involves an intricate relationship between the atlas and the axis to allow flexion, extension, rotation, and lateral bending. ${ }^{9}$ The interrelation of osseous, ligamentous, neural elements and articulation make the atlantoaxial junction vulnerable to instability and potentially devastating neurologic complications (quadriplegia, diaphragmatic paralysis and sudden death). ${ }^{20}$

The lateral masses have large, concaved and superior surfaces to articulate with the occipital condyles. They are directed upward, medially and backward and form a cup for the corresponding condyles. The inferior surfaces are circular and directed downward and medially to articulate with the superior articulating facet of C2 and form the zygapophyseal joints, which allows flexion-extension, side bending, and rotational movements. The atlantoaxial joints are the articulation between $\mathrm{C} 1$ and $\mathrm{C} 2$ and have a range of motion in the transverse plane for rotation. This rotation is facilitated by the odontoid process, which acts as a pivot joint for the rotation of $\mathrm{C} 1 .^{20}$ The atlantoaxial articulation is composed of three synovial joints: the paired lateral mass articulation and the central articulation between the dens and the anterior arch of $\mathrm{C} 1$ and the transverse ligament. ${ }^{21}$ So, depth understanding of the complex anatomy and biomechanical uniqueness of CVJ is utmost essential prior to the surgery.

The first description of the cervical spine involvement in patients with RA dates to 1890 and was made by Sir Archibald Edward Garrod..$^{21}$ RA is the most common inflammatory disease involving the cervical spine, ${ }^{22}$ and anterior atlantoaxial subluxation, resulting from laxity of the primary and secondary ligamentous restraints, is the most common cervical deformity associated with RA. ${ }^{23}$ The involvement of the atlantoaxial articulation may lead to severe neurological symptoms and even to death from acute respiratory failure due to brainstem compression. ${ }^{24}$ Because of its potentially lethal effects, cervical spine involvement in RA should be promptly diagnosed and treated. Biologic agents are often sufficient to slow the progression of the disease, but early surgical intervention is often required, especially for RA patients with neurological deficits. ${ }^{25}$

Destabilization of the atlantoaxial joint is multifactorial and can lead to pathologic motion with neurologic sequelae.
Static stability is conferred by both osseous and ligamentous contributions consisting primarily of the facet articulations, dens and fovea dentis, the facet capsule, and the TAL. Dynamic stability arises from the multiple muscular attachments of the anterior arch and transverse process. Trauma, congenital malformations, inflammatory arthritides (RA), and malignancy have been implicated in the development of atlantoaxial instability. Since the first description of surgical treatment by Mixter and Osgood in 1910, multiple techniques have been described to provide atlantoaxial stability in an effort to protect the space available for the spinal cord and prevent basilar invagination. ${ }^{26}$

When evaluating suspected AAD, following trauma, current guidelines recommended are CT scan of CVJ followed by MRI to assess ligamentous injury and preferably within 72 hours, as after 72 hours, there is decreased tissue edema and results in ligamentous injury which may lead to underdiagnosis. The vital ligament looked for is TAL.

Revisiting the article of Goel's C1 lateral mass screw with C2 pars or pedicle screw fixation, where the authors achieved $100 \%$ fusion with minimal rate of complications. $^{7}$ The authors advocate bilateral sacrifice of C2 ganglia to prepare the atlantoaxial facet joints for arthrodesis. We too sacrificed C2 ganglia in two cases without much sensory upset. Goel et al have highlighted the advantage of their method over other constructs. ${ }^{7}$ One of the advantages of the C1 lateral mass in combination with $\mathrm{C} 2$ screw technique is that anatomic alignment of the $\mathrm{C} 1-\mathrm{C} 2$ complex is not necessary prior to instrumentation. ${ }^{7}$

RA more commonly involved in women than men. Atlantoaxial instability is the most common form of cervical involvement and may occur either independently or concomitantly with cranial settling and subaxial instability. ${ }^{22}$ Cervical spine involvement can be seen in up to $86 \%$ of patients and neurologic involvement in up to $58 \% .^{22}$ The goal is to identify the patients at risk before the development of neurologic symptoms, because pain cannot be equated with instability or instability with neurologic symptoms..$^{22,27}$ Failure of fusion results in a persistent ossiculum terminale (also known as ossiculum terminale of Bergmann) and is considered a normal anatomical variant of the axis. It lies above the TAL and is therefore deemed to be stable, and it very rarely causes symptoms. ${ }^{28,29}$ Os odontoideum, whether the result of congenital osseous malformation or prior unrecognized trauma, requires the same radiologic and clinical workup. Surgical stabilization of the upper cervical spine has been proposed for progressive symptomatology, including intractable neck pain, transient or progressive myelopathy, vertebral artery insufficiency and worsening instability. ${ }^{30,31}$ From the consecutive case series of 71 RA patients by Yan et al, the instability of the atlantoaxial joint, including anterior atlantoaxial subluxation, posterior atlantoaxial subluxation and anterior-posterior atlantoaxial subluxation were found in 68 cases (95.7\%), while rotation subluxation was presented in 37 cases $(52.1 \%)$. Vertical migration of the odontoid was seen in 11 cases (15.5\%). Rheumatoid factor was positive in 18 cases $(25.3 \%){ }^{32}$ Patients who have os odontoideum 
with a reducible atlantoaxial dislocation can be effectively treated with single-level posterior fusion and stabilization. The differential diagnosis for os odontoideum typically includes ossiculum terminale and type II odontoid fracture. ${ }^{33}$ The former appears as a secondary ossification center of the dens between 3 and 6 years of age and normally fuses by the age of 12 years. Posterior $\mathrm{C} 1-\mathrm{C} 2$ screw and rod fixation with spacer or autologous corticocancellous bone is regarded as safe and efficient technique for fixation $A A D$ in terms of complications, biomechanical stability and fusion rate. Yeom et al showed that 8 of the 39 (20.5\%) C2 pedicle screws caused $\mathrm{C} 1-\mathrm{C} 2$ fusion in atlantoaxial instability, 21 (54\%) vertebral artery groove violation, and two of the 39 (5.1\%) C1 lateral mass screws showed evidence of cortical violation at $\mathrm{C} 1$ with one undetected vertebral artery injury. ${ }^{10}$

In our patient 1 , who was a female of fifth decade the C1-C2 instability was due to RA, and there is clear evidence of neurologic deficits. The RA is a slow and progressive chronic inflammatory pathology where anatomical supports at the $\mathrm{CVJ}$ lost over the time. $\mathrm{C} 1-\mathrm{C} 2$ anterolisthesis and retrolisthesis may cause cervicomedullary injury both from anterior and posterior aspects and commonly leads to reducible AAD.

The patient of os odontoideum in adult variety presented to the hospital with trivial history of trauma or fall, which may be often ignored as cause of neurological deterioration.

The os odontoideum is a congenital anomaly/posttraumatic event of $\mathrm{C} 2$ vertebra, in which the odontoid process is separated from the body of the axis by a transverse gap, and it is a smooth, well-corticated ossicle. ${ }^{34}$ An "orthotopic" type is closely approximated to $\mathrm{C} 1$ anterior arch and moves in unison with it, and a "dystopic" one is intimately related to the clivus. In our case series following posterior $\mathrm{C} 1-\mathrm{C} 2$ fixation (polyaxial screw and rod) \pm fusion, we found the best short-term clinical outcomes, and sufficient literatures support the satisfactory fusion rate over time. However, successful outcome depends upon preoperative assessment and meticulous surgical technique. As mentioned earlier, we found satisfactory screw placement, alignment and reductions intraoperatively, which were confirmed by postoperative images too. We found current technique most versatile, simple and technically sound, which allows intraoperative direct manipulation of C1-C2 and does not require continuous fluoroscopic imaging. One more important aspect of this technique is there is less risk of vertebral artery injury because of trajectory of screw directed toward medial and superior and no facet joint destruction when we compared with transarticular screw fixation (Magerl). Also, transarticular screw fixation is technically demanding and requires continuous fluoroscopy.

There is general consensus that type I and type III odontoid fracture can be managed with hard cervical collar (rigid cervical orthosis) in most cases. Type II odontoid fracture is usually associated with AAD (most common is type-IIA), having lower union rate. The current treatment modalities for type-II odontoid fracture include anterior (transoral odontoidectomy, odontoid screw) and posterior instrumentation (C1-C2 arthrosis, occiput cervical fusion). Other modalities of treatment include rigid cervical orthosis and halo vest immobilization. In young patients with acute type-II odontoid fracture, posterior C1-C2 fixation without fusion may be sufficient for fracture healing. The factors affecting healing of type II odontoid fracture included age, bone density, types and classification of fracture (degree of displacement and comminution), old fracture, and smoking.

The purpose of cervical stabilization is to provide symptoms free life, stability of craniospinal axis and alignment, and halt the progression of neurological deficits by relieving the compression to spinal cord.

A purely traumatic AAD in the absence of odontoid fracture and associated other osseous injury is rare. Traumatic AAD is due to high velocity injury following disruptions of transverse ligaments. If we compare occipitocervial fusion (OCF) and atlantoaxial fusion (AAF), AAF provides greater range of motion at $\mathrm{C} 0-\mathrm{C} 1$ segment and better subjective satisfaction to the patients. However, clinical outcome, complication rate and infection study conducted in elderly population in between above two procedures appear to be same. ${ }^{35}$

Again, deciding the treatment for type II odontoid fracture remains upon the type of fracture, local pathologies, and surgeon's preference. To date, there are no well-controlled trials and studies to infer the true merits and demerits of the different treatment and approaches. So, no single ideal technique is found to be so effective for the treatment of odontoid fracture. ${ }^{36}$

\section{Conclusion}

Posterior C1-C2 screw and rod fixation (Goel-Harms) can be regarded as safe and efficient technique for fixation of AAD in terms of minimal complications, more biomechanical stability, increased pull out strength and fusion rate. This technique may be considered as procedure of choice when it satisfies the criteria. Early detection of atlantoaxial dislocation is the key for successful management of the atlantoaxial dislocation in terms of symptomatic and neurological improvement and halting the progression of the spinal cord disease process.

\section{Conflict of Interest}

None declared.

\section{References}

1 Atlanto-axial Arthrodesis by the Wedge Compression Method. Availableat:https://pubmed.ncbi.nlm.nih.gov/348703/.Accessed November 29, 2020

2 Gallie WE. Fractures and dislocations of the cervical spine. Am J Surg 1939;46(3):495-499

3 Dickman CA, Sonntag VKH, Papadopoulos SM, Hadley MN. The interspinous method of posterior atlantoaxial arthrodesis. J Neurosurg 1991;74(2):190-198

4 Reilly TM, Sasso RC, Hall PV. Atlantoaxial stabilization: clinical comparison of posterior cervical wiring technique with transarticular screw fixation. J Spinal Disord Tech 2003;16(3):248-253 
5 Magerl F, Seemann P-S, Stable posterior fusion of the atlas and axis by transarticular screw fixation. In: Pierre K, Andreas W, eds. Cervical Spine I. Vienna: Springer; 1987:322-7

6 Currier BL, Yaszemski MJ. The Use of C1 Lateral Mass Fixation in the Cervical Spine. Available at: https://mayoclinic.pure. elsevier.com/en/publications/the-use-of-c1-lateral-mass-fixation-in-the-cervical-spine. Accessed November 29, 2020

7 Goel A, Laheri V. Plate and screw fixation for atlanto-axial subluxation. Acta Neurochir (Wien) 1994;129(1-2):47-53

8 Harms J, Melcher RP. Posterior C1-C2 fusion with polyaxial screw and rod fixation. [Internet] Spine 2001;26(22):2467-2471

9 Fractures of the Odontoid Process of the Axis. Available at: https://pubmed.ncbi.nlm.nih.gov/4434035/. Accessed November 29, 2020

10 Hadley MN, Browner CM, Liu SS, Sonntag VK. New subtype of acute odontoid fractures (type IIA). Neurosurgery 1988;22(1 Pt 1):67-71

11 Grauer JN, Shafi B, Hilibrand AS, et al. Proposal of a modified, treatment-oriented classification of odontoid fractures. Spine J 2005;5(2):123-129

12 Anterior Stabilization for Acute Fractures and Non-Unions of the Dens.. Available at: https://pubmed.ncbi.nlm.nih. gov/7033229. Accessed November 29, 2020/

13 Crisco, JJ, Oda, T, Panjabi, MM, Bueff, HU, Dvorak, J, Grob, D. Transections of the C1-C2 Joint capsular ligaments in the cadaveric spine. Spine 1991;16(10, Suppl):S474-S479

14 The Upper Cervical Spine. Regional Anatomy, Pathology and Traumatology. A Systematic Radiological Atlas and Textbook. Available at: https://www.ncbi.nlm.nih.gov/pmc/articles/ PMC1271692/. Accessed November 29, 2020

15 Lopez AJ, Scheer JK, Leibl KE, Smith ZA, Dlouhy BJ, Dahdaleh NS. Anatomy and biomechanics of the craniovertebral junction. Neurosurg Focus 2015;38(4):E2

16 Oda, T, Panjabi, MM, Crisco, JJ, Oxland, TR, Katz, L, Nolte, L-P. Experimental Study of Atlas Injuries II. Spine 1991; 16(10, Suppl):S466-S473

17 Measurement of the Atlanto-dental Interval in the Adult. Available at: https://pubmed.ncbi.nlm.nih.gov/13714428/. Accessed November 29, 2020

18 Clark CR, White AA. Fractures of the Dens. A Multicenter Study. Available at: https://europepmc.org/article/med/4077905. Accessed November 29, 2020

19 Dvorak J, Schneider E, Saldinger P, Rahn B. Biomechanics of the craniocervical region: the alar and transverse ligaments. J Orthop Res 1988;6(3):452-461

20 Quinones-Hinjosa A, Schmidek and Sweet: Operative Neurosurgical Techniques. Indication, Methods, and Results. 2 Volume Set. Philadelphia: Elsevier; 2012

21 Steilen D, Hauser R, Woldin B, Sawyer S. Chronic neck pain: making the connection between capsular ligament laxity and cervical instability. Open Orthop J 2014;8(1):326-345
22 Vu Nguyen H, Ludwig SC, Silber J, et al. Rheumatoid arthritis of the cervical spine. Available at: https://pubmed.ncbi.nlm.nih. gov/15125859/. Accessed November 29, 2020

23 Rheumatoid Arthritis of the Cervical Spine-Clinical Considerations. Available at: https://pubmed.ncbi.nlm.nih.gov/ 22035393/. Accessed November 29, 2020

24 Reijnierse M, Dijkmans BAC, Hansen B, et al. Neurologic dysfunction in patients with rheumatoid arthritis of the cervical spine. Predictive value of clinical, radiographic and MR imaging parameters. Eur Radiol 2001;11(3):467-473

25 Cha TD, An HS. Cervical spine manifestations in patients with inflammatory arthritides. Nat Rev Rheumatol 2013;9(7):423-432

26 Yang SY, Boniello AJ, Poorman CE, Chang AL, Wang S, Passias PG. A review of the diagnosis and treatment of atlantoaxial dislocations. Global Spine J 2014;4(3):197-210

27 Gunnarsson T, Massicotte EM, Govender PV. Raja Rampersaud Y, Fehlings MG. The use of C1 lateral mass screws in complex cervical spine surgery: indications, techniques, and outcome in a prospective consecutive series of 25 cases. J Spinal Disord Tech 2007;20(4):308-316

28 Viswanathan A, Whitehead WE, Luerssen TG, Illner A, Jea A. "Orthotopic" ossiculum terminale persistens and atlantoaxial instability in a child less than 12 years of age: a case report and review of the literature. Cases J 2009;2(8):8530

29 Johal J, Loukas M, Fisahn C, Oskouian RJ, Tubbs RS. Bergmann's Ossicle (ossiculum terminale persistens): A Brief Review and Differentiation from Other Findings of The Odontoid Process. Vol. 32, Child's Nervous System. Berlin Heidelberg: Springer; 2016 1603-6

30 Hensinger RN. Osseous anomalies of the craniovertebral junction. Spine 1986;11(4):323-333

31 Hughes TB, Jr, Richman JD, Rothfus WE. Diagnosis of Os odontoideum using kinematic magnetic resonance imaging. A case report. Spine 1999;24(7):715-718

32 Clinical Characteristics and Diagnosis of Rheumatoid Arthritis of Upper Cervical Spine: Analysis of 71 Cases. Available at: https://pubmed.ncbi.nlm.nih.gov/18756956/. Accessed November 29, 2020

33 Arunbalaji SS, Jothi R. Trivial trauma with atlantoaxial instability in Os odontoideum: Need for cervical fusion. J Spinal Stud Surg [Internet] 2017;1(2):35

34 Os Odontoideum. Available at: https://pubmed.ncbi.nlm.nih. gov/7364809/. Accessed November 29, 2020

35 Wenning KE, Hoffmann MF. Does isolated atlantoaxial fusion result in better clinical outcome compared to occipitocervical fusion? J Orthop Surg Res 2020;15(1):8

36 Treatment of Odontoid Fractures: A Clinical Challenge and Reality. Available at: https://www.semanticscholar.org/ paper/Treatment-of-odontoid-fractures\%3A-A-clinical-andKutbe/3a894fded5b1a41b719368626e5d67744840cfe7. Accessed November 29, 2020 